\title{
Avaliação de diferentes densidades de semeadura e da poda na produtividade de sementes de Crotalaria juncea L. $^{1}$
}

\author{
Priscila Pixoline Eiras², Fábio Cunha Coelho ${ }^{3}$
}

\begin{abstract}
RESUMO
Verifica-se, atualmente, crescente interesse na prática de adubação verde e em seus efeitos nos sistemas produtivos agrícolas. Com o objetivo de avaliar diferentes densidades de semeadura e efeitos da poda na produção de sementes de Crotalaria juncea L., foi conduzido experimento na Unidade de Apoio à Pesquisa, na UENF, em Campos dos Goytacazes - RJ. O arranjo experimental foi em parcelas subdivididas, escolhendo-se como parcelas a presença e a ausência de poda e, como subparcelas, as densidades de semeio (10, 15, 20, 25 e 30 planta por metro). O delineamento foi em blocos casualizados, com quatro repetições. As unidades experimentais foram constituídas por seis linhas, com espaçamento de $0,5 \mathrm{~m}$, com 4 metros de comprimento. Sem poda, a crotalária apresentou-se $0,634 \mathrm{~m}$ mais alta. O número de ramos de crotalária nas plantas podadas foi maior que o das não podadas e as densidades de 10 e 15 plantas 'por metro apresentaram maiores números de ramos. A densidade 30 apresentou maior quantidade de matéria seca. Com poda, a crotalária apresentou média de 7,2 vagens pequenas, enquanto, as plantas não podadas apresentaram média de 5,1 vagens pequenas. Quando se utilizou a densidade de 30 plantas por metro, ocorreram aproximadamente $25 \%$ a mais de sementes por vagem grande, nas plantas podadas, em relação às sementes das vagens grandes das plantas não podadas. Além disto, esta densidade apresentou maior número de sementes por vagem grande, em relação às das demais densidades. Recomenda-se a poda e a densidade de 10 plantas por metro, por menor gasto com sementes e sementes com maior vigor.
\end{abstract}

Palavras-chave: Fabaceae, adubação verde, sistema de MEIOSI.

\section{ABSTRACT}

\section{Evaluation of different plant densities and pruning in seed yield of Crotalaria juncea $\mathrm{L}$.}

There is currently a growing interest in the practice of green manure and its effects on agricultural production systems. In order to evaluate different seeding rates and effects of pruning on seed production of C. juncea an experiment was conducted in the Unit of Research Support in UENF in Campos - RJ. The experiment was arranged in split-plots, with pruning (and without) in the plots and sowing densities $(10,15,20,25$ and 30 per plant) in the subplots in a randomized block design with four replications. The experimental units consisted of six rows spaced $0.5 \mathrm{~m}$ apart, and 4 feet long. Without pruning, crotalaria plants were $0.634 \mathrm{~m}$ higher. The number of branches of pruned crotalaria plants was larger than the non-pruned plants and the density of 10 and 15 plants per meter had lager number of branches. At the density of 30 plants per meter, the plants produced higher amount of dry matter. With pruning, the crotalaria plants showed on average 7.2 small pods, while the non-pruned plants had mean of 5.1 small pods. At the density of 30 plants per meter, there was approximately $25 \%$ more seeds per large pod of pruned plants in relation to the seeds of large pods of non-pruned plants. Besides, at this density, plants had larger number of seeds per large pod compared with other densities. It is recommended pruning and density of 10 plants per meter due to the lower cost of seeds and seeds with more vigor.

Key words: legume, green manure, MEIOSI system.

\footnotetext{
Recebido para publicação em 24/03/2010 e aprovado em 01/03/2012.

${ }^{1}$ Extraído da Dissertação apresentada pela primeira autora ao Programa de Pós-Graduação em Produção Vegetal do Centro de Ciências e Tecnologia Agrárias (CCTA) da Universidade Estadual do Norte Fluminense Darcy Ribeiro (UENF), Campos dos Goytacazes, Rio de Janeiro.

2 Engenheira-Agrônoma, Mestre. Universidade Estadual do Norte Fluminense (UENF), Avenida Alberto Lamego, 2000, Parque Califórnia, 28013-602, Campos dos Goytacazes, Rio de Janeiro, Brasil. priscilapixoline@yahoo.com.br

${ }^{3}$ Engenheiro-Agrônomo, Doutor. Departamento de Fitotecnia, Universidade Estadual do Norte Fluminense (UENF), Avenida Alberto Lamego, 2000, Parque Califórnia, 28013602, Campos dos Goytacazes, Rio de Janeiro, Brasil. fcoelho@uenf.br
} 


\section{INTRODUÇÃO}

Verifica-se, atualmente, crescente interesse na prática de adubação verde e em seus efeitos nos sistemas produtivos agrícolas por, principalmente, produtores rurais e demais agentes ligados ao setor agropecuário, especialmente onde a preocupação com a conservação e melhoria do ambiente é mais acentuada. Na tentativa de minimizar a degradação acelerada da fertilidade dos solos, principalmente em relação à matéria orgânica, vêm sendo utilizados adubos verdes, os quais apresentam a capacidade de melhorar as propriedades físicas, químicas e biológicas do solo.

Segundo Dourado et al. (2001), a prática de adubação verde, embora apresente várias vantagens, é pouco utilizada pelos agricultores, principalmente durante o verão, pois, para eles, o cultivo de uma espécie de adubo verde não propicia retorno econômico imediato, ou seja, ocupa o espaço de outra cultura de renda. Isto ocorre em função do desconhecimento dos efeitos benéficos das plantas de cobertura nos sistemas de produção. Por outro lado, Skora Neto (1993) sugere que é desejável que a adubação verde seja considerada uma prática economicamente rentável.

Em estudos, Wildner (1992), em Santa Catarina, destacou a utilização de adubos verdes como cobertura do solo, possibilitando, além do controle da erosão, a diminuição da incidência de plantas daninhas, a redução das perdas de nutrientes, a atenuação das flutuações da temperatura do solo, contribuindo para a recuperação de áreas degradadas pelo mau uso do solo. Portanto, manter a cobertura pelo maior tempo possível é fundamental no manejo racional do solo.

Estudos têm demonstrado o grande potencial dos adubos verdes na recuperação da produtividade do solo. Um dos principais desafios está em estabelecer um esquema de uso compatível das diferentes espécies com os sistemas de produção específicos de cada região, se possível nos limites de cada propriedade, levando-se em consideração os aspectos ligados ao clima, solo, infraestrutura da propriedade e condições socioeconômicas do agricultor (Calegari et al., 1992). A utilização dessas plantas pode visar, além da conservação ou melhoria da fertilidade do solo, à própria produção de sementes como fonte de renda (Bulisani, 1992). Esse crescimento na utilização de adubação verde tem aumentado a necessidade de disponibilizar sementes de qualidade no mercado (Calegari et al., 1992). Deve-se considerar também o rendimento de produção das plantas ou quantidade de sementes produzidas.

Diversas espécies da família das Fabaceas têm sido utilizadas com a finalidade de adubação verde, sendo uma destas a crotalária (Crotalaria juncea L.). Esta planta é caracterizada por ser de fotoperíodo curto, isto é, tem o seu florescimento induzido em dias de curta duração (Calegari et al., 1992).

É de grande importância o conhecimento da época ideal para plantio e colheita, na tentativa de se obter, na época da retirada das vagens do campo, sementes de máxima qualidade e quantidade, sendo vantajoso para o agricultor adquirir sementes desse padrão para a sua posterior utilização no campo, resultando em elevada relação custo/benefício.

Na Região Norte Fluminense, o interesse pela crotalária é devido ao sistema "MEIOSI" (Método Interrotacional Ocorrendo Simultaneamente) de produção em áreas de reforma de canavial, buscando a redução de custo de plantio. Esse sistema consiste no plantio de cana de ano e meio, com o início de uma parte do plantio em setembro/ outubro, na proporção de 3:10 (plantio de três linhas e espaço equivalente a dez), com o objetivo de produzir mudas suficientes na própria área em reforma para o plantio da área total em março/abril. Nos espaços intercalares, tem-se a possibilidade da instalação de culturas que tenham ciclo compatível ao do sistema "MEIOSI", ou seja, culturas que possam ser plantadas e colhidas durante o período do desenvolvimento da muda de cana-de-açúcar, com destaque para o adubo verde Crotalaria juncea, pela capacidade de produção de grande quantidade de massa verde em curto tempo.

O custo da semente no mercado está na faixa de $\mathrm{R} \$$ 5,00 a 9,00 por quilo, o que torna a prática do sistema de MEIOSI desestimulante para os pequenos e médios produtores.

Logo, sabendo-se que a produtividade média de sementes de crotalária citada está em torno de 500 a $1000 \mathrm{~kg}$ $\mathrm{ha}^{-1}$, de acordo com a população de plantas e condições edafoclimáticas (Calegari et al., 1992), o produtor poderá produzir sua própria semente.

A crotalária é uma planta de ciclo anual, ereta, arbustiva, de crescimento determinado. Quando a cultura é destinada a produção de sementes, deve-se realizar a semeadura entre março e abril, visando à obtenção de plantas mais baixas e maior facilidade de colheita das sementes. Porém, quando se utiliza a poda, pode-se realizar a semeadura entre outubro e novembro (Dourado, 2001).

O objetivo deste trabalho foi avaliar diferentes densidades de semeadura e efeitos da poda na produtividade de sementes de Crotalaria juncea L.

\section{MATERIAL E MÉTODOS}

Foi instalado um experimento de campo na Unidade de Apoio à Pesquisa (UAP), na Universidade Estadual do Norte Fluminense Darcy Ribeiro, no município de Campos dos Goytacazes, no norte do Estado do Rio de Janeiro, situada a $21^{\circ} 19^{\prime} 23^{\prime \prime} \mathrm{S}$ de latitude, $41^{\circ} 10^{\prime} 40^{\prime \prime} \mathrm{W}$ de 
longitude e altitude de $14 \mathrm{~m}$, durante o período de novembro de 2008 a março de 2009.

$\mathrm{O}$ arranjo experimental foi em parcelas subdivididas, tomando-se como parcela presença e ausência de poda e, como subparcelas, os estandes iniciais $(10,15,20,25$ e 30 plantas por metro). O delineamento foi em blocos casualizados, com quatro repetições.

As unidades experimentais foram constituídas por seis linhas com espaçamento de 0,5 m, com 4 metros de comprimento, utilizando-se como área útil as quatro linhas centrais, desconsiderando-se $0,5 \mathrm{~m}$ em cada extremidade da parcela.

A Crotalaria juncea foi semeada manualmente, em área preparada pelo sistema convencional (uma aração e duas gradagens) e em seguida a área foi sulcada. Realizou-se o semeio de $50 \%$ a mais de sementes e, após o crescimento, foi feito desbaste. A adubação de base foi calculada em função dos resultados da análise química do solo, sendo aplicados $90 \mathrm{~kg} \mathrm{ha}^{-1}$ de $\mathrm{P}_{2} \mathrm{O}_{5}$, conforme recomendação para feijão Phaseolus vulgaris (Alvarez et. al., 1999).

A poda foi realizada manualmente, de acordo com a altura estabelecida, de um metro, por Dourado et al. (2001), com tesouras de poda, aos 60 dias após a emergência das plântulas, para obtenção de aumento na produção de sementes.

A altura de plantas foi determinada em 10 plantas por unidade experimental, medindo-se, com régua, desde a superfície do solo até a gema do ramo mais alto da planta, sendo este nas plantas não podadas o ramo principal e nas plantas podadas o ramo de maior comprimento, aos 150 dias após a emergência das plântulas (no ato da colheita). O diâmetro do caule de plantas foi medido com paquímetro (em milímetro), a cerca de $15 \mathrm{~cm}$ da superfície do solo, em 10 plantas amostradas aleatoriamente, aos 150 dias após a emergência das plântulas (no ato da colheita). O número de ramos por planta foi contado em 10 plantas por unidade experimental, aos 150 dias após a emergência das plântulas. O peso da matéria seca por planta e por área foi determinado em 10 plantas por unidade experimental, coletadas em uma das duas linhas centrais, aos 150 dias após a emergência das plântulas (no ato da colheita). O material foi pesado, secado em estufa com ventilação forçada, à temperatura de $70^{\circ} \mathrm{C}$, por $72 \mathrm{~h}$. As vagens por planta foram determinadas a partir da contagem das vagens de uma das linhas centrais de cada unidade experimental, no momento da colheita, padronizando dois grupos de comprimentos de vagens. Assim, ocorreu a separação das vagens de até $1,50 \mathrm{~cm}$; entre 1,51-2,50 $\mathrm{cm}$ (vagens pequenas) e; acima de $2,51 \mathrm{~cm}$ de comprimento (vagens grandes). As vagens de até $1,50 \mathrm{~cm}$ foram descartadas, por causa de seu menor desenvolvimento. As sementes por vagem foram obtidas pela contagem do número de sementes de 10 vagens, de comprimento entre 1,51-2,5 cm, e de 10 vagens de comprimento acima de 2,51 $\mathrm{cm}$. As sementes oriundas de vagens com comprimento abaixo de 1,5 cm não foram contadas, por seu menor desenvolvimento. Foram utilizadas oito subamostras de 100 sementes, provenientes da porção semente pura de cada UE, para determinar o peso de 1.000 sementes. As sementes foram contadas manualmente e, em seguida, pesadas em balança analítica, com precisão de 0,0001g (Brasil, 2009). O resultado de peso médio foi multiplicado por 10 e expresso em gramas. O rendimento de grãos foi determinado na linha central de cada unidade experimental, descartando-se 0,5 m das extremidades, quando cerca de $70 \%$ das vagens estavam secas.

O experimento foi analisado estatisticamente, utilizando-se o Software SAEG - Sistema para Análises Estatísticas (SAEG, 2000). Utilizou-se a estatística descritiva, comparando-se as médias por meio de seus erros padrão, considerando-as como diferentes quando estas tinham erros padrão das médias que não se interpunham.

\section{RESULTADOS E DISCUSSÃO}

Sem poda, a crotalária apresentou-se 0,634 m mais alta e com diâmetro de $1,17 \mathrm{~mm}$ a mais que a crotalária podada (Figura 1). Diâmetro diferente nas plantas podadas e não podadas foi resultado que corrobora os obtidos por Dourado et al. (2001), em cujo trabalho a maior média (10,30 $\mathrm{mm}$ ) ocorreu nas plantas que não receberam a poda.

O número de ramos da crotalária nas plantas podadas foi maior, com aproximadamente dois ramos a mais que nas plantas não podadas (Figura 1). Isto ocorreu, possivelmente, pela quebra da dominância apical, devido à poda do caule, resultando em menor concentração de auxina nas gemas axilares das folhas e, consequentemente, indução da brotação de ramos laterais. As auxinas, além de promoverem a distensão celular, quando distribuídas caule abaixo, inibem a atividade das gemas laterais (Taiz \& Zeiger, 2002). Assim, quando a gema apical da planta é retirada, as gemas laterais saem da dormência, isto é, da dominância apical, e ramos laterais desenvolvem-se. Dourado et al. (2001) obtiveram resultados diferentes, chegando a afirmar que a prática da poda não afeta o número de ramos em crotalária.

Foi visualmente observado que os ramos laterais das plantas podadas eram maiores que os das não podadas. Possivelmente, ocorreu maior distribuição de nutrientes minerais das raízes para os ramos laterais em decorrência da ausência de parte do ramo principal que foi podado, com isto os ramos laterais desenvolveram-se mais. As densidades de 20 e 30 plantas por metro apresentaram resultados inferiores aos das densidades 10 e 15, possivelmente por maior competição entre plantas nas densidades maiores (Figura 2). 
Observou-se efeito da poda sobre a quantidade de matéria seca produzida por planta. As plantas podadas apresentaram 5,8 $\mathrm{g}$ de matéria seca a menos que as não podadas (Figura 1). A poda, apesar de ter resultado em maior número de ramos (Figura 1), os quais, constatou-se que foram maiores do que os das plantas da parcela não podada, levou à diminuição do peso da matéria seca das plantas. Certamente, a região do caule retirada pela poda foi a causa desta redução do peso das plantas.

Os resultados obtidos discordam dos de Dourado \& Almeida (1998), que afirmaram ser a prática da poda não prejudicial à produção de matéria seca total da planta, quando comparada à do tratamento sem poda. É bem provável que as condições ambientais afetem essa característica, não sendo possível generalizar para todas as regiões ou situações edafoclimáticas.

Entretanto, a produção de matéria seca por área, não foi afetada pela poda (Figura 1). As plantas de crotalária apresentaram produção de matéria seca dentro da faixa de variação mencionada por Wutke (1993) para a Crotalaria juncea L., entre 10 e $15 \mathrm{Mg} \mathrm{ha}^{-1}$. A elevada produção de fitomassa da leguminosa, em curto período, revela que esta espécie encontra-se adaptada às condições ambientais do experimento, podendo ser considerada como espécie potencial para o sistema de "MEIOSI".

Apesar de a produção de matéria seca por área não ter sido afetada pela poda (Figura 1), vale ressaltar que este manejo deve ser considerado como inadequado, quando se quer maior produção de matéria seca, como para adubação verde. No entanto, o objetivo da poda, neste experimento, foi a produção de sementes na época do verão.

A densidade de plantas não afetou a quantidade de matéria seca produzida por planta resultando $34,6 \pm 1,8 \mathrm{~g}$ por planta. Nota-se, porém, que 30 plantas $\mathrm{m}^{-1}$ resultaram em maior quantidade de matéria seca, por área, em relação às demais densidades (Figura 3); isto se deve ao maior

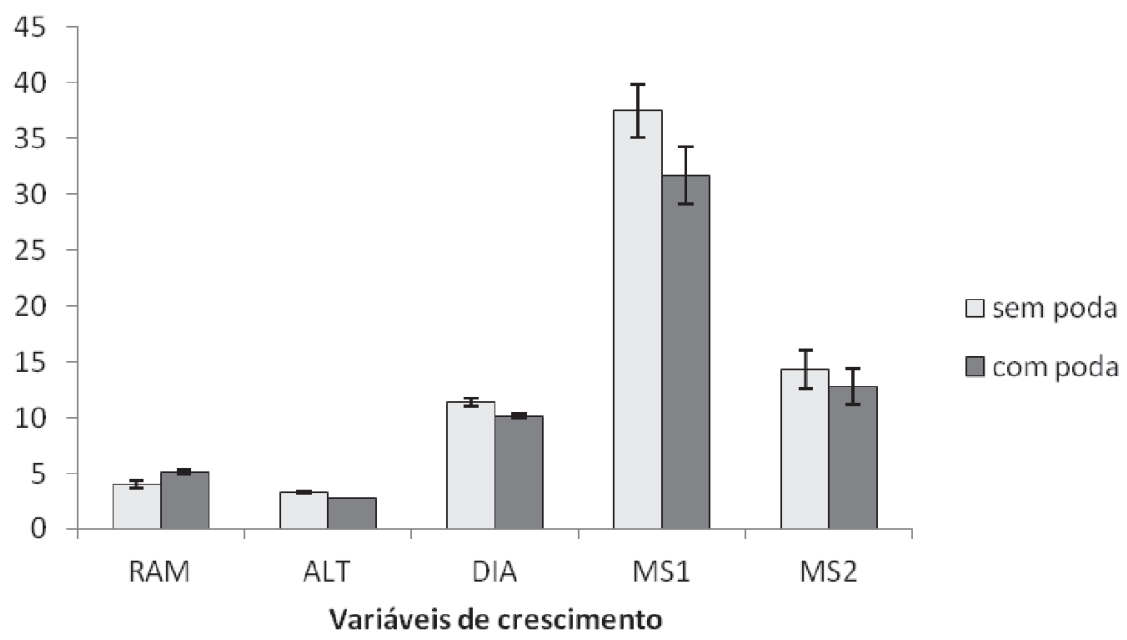

Figura 1 - Médias das variáveis de crescimento de Crotalaria juncea avaliadas aos 150 dias de cultivo (colheita), em resposta aos manejos de ausência e presença de poda. (RAM = número de ramos; ALT = altura das plantas em m; DIA = diâmetro do caule em mm; MS1= matéria seca em $\mathrm{g}$ por planta e MS2 = matéria seca em $\left.\mathrm{Mg} \mathrm{ha}^{-1}\right)$.

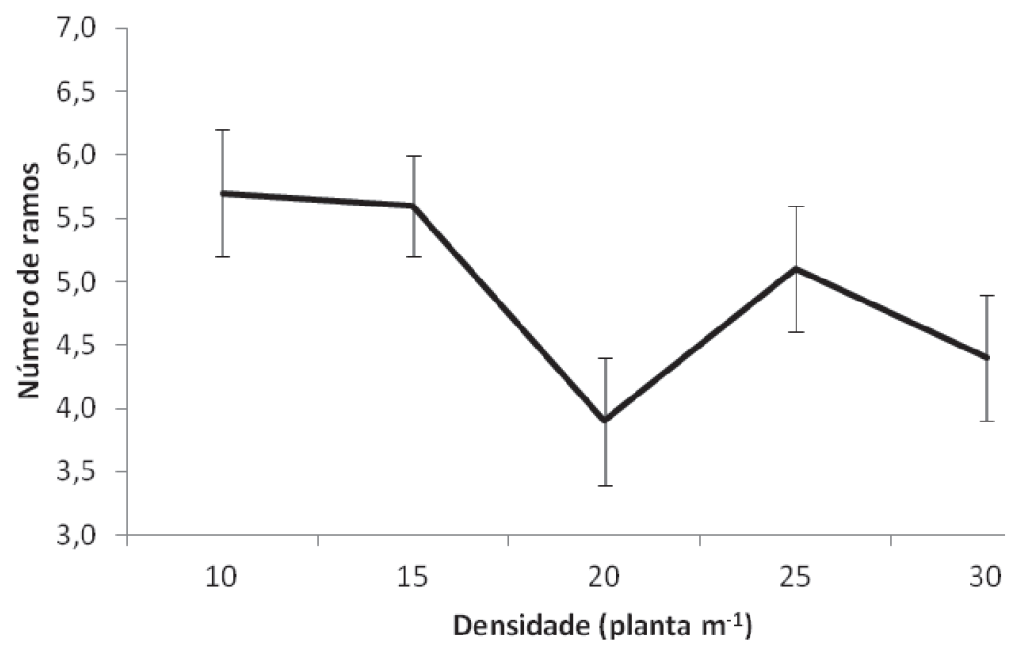

Figura 2 - Número de ramos por planta de Crotalaria juncea obtidos nas densidades de plantio de 10, 15, 20, 25 e 30 plantas por metro, aos 150 dias de cultivo (colheita). 
número de plantas por área. Os menores valores foram obtidos com 10 e 15 plantas por metro, enquanto valores intermediários ocorreram com 20 e 25 plantas por metro (Figura 3).

Duarte \& Coelho (2008) avaliaram diferentes espécies de adubos verdes e seus efeitos no rendimento da canade-açúcar e observaram que, com crotalária aos 92 dias após a emergência, obteve-se maior produtividade de matéria seca ( $\left.17.852 \mathrm{~kg} \mathrm{ha}^{-1}\right)$, valor de 1,6 vezes maior que a média do feijão-de-porco com a mucuna-preta. Semelhantemente, em Cambissolo, Perin et al. (2004) verificaram que, com a crotalária aos 68 dias após o plantio (DAP), também houve maior produção de fitomassa (9.340 $\mathrm{kg} \mathrm{ha}^{-1}$ ), inclusive em relação à da vegetação espontânea, discordando dos resultados de Nascimento \& Silva (2004), que avaliaram 12 espécies de Fabaceae para uso como adubo verde, em um experimento em Alagoinha-PB, e observaram que a crotalária foi a menos responsiva para produção de matéria seca, com uma produção de $1.970 \mathrm{~kg}$ $\mathrm{ha}^{-1}$, resultado muito inferior ao obtido no presente trabalho (Figura 1).

Amabile et al. (2000), em Senador Canedo - GO, avaliaram a semeadura de crotalária, no início, meados e final da estação chuvosa, com corte das plantas ao atingirem $50 \%$ de florescimento, que ocorreu aos 118, 88 e 67 dias após a semeadura. A produção de fitomassa seca foi de 17,27; 7,99 e 6,00 $\mathrm{Mg} \mathrm{ha}^{-1}$, respectivamente. O resultado aos 118 dias foi maior, em comparação com as produções obtidas no presente trabalho, o que pode ser justificado pela perda de fitomassa quando a planta é cultivada para produção de sementes.

Com poda, a crotalária produziu 7,2 $\pm 0,8$ vagens pequenas, enquanto, nas plantas não podadas, obtiveramse 5,1 $\pm 0,4$ vagens pequenas. Para vagens grandes, não houve efeito de poda; em média foram encontradas 7,2 \pm 0,4 vagens grandes por planta.
A poda resultou em aumento no número de vagens grandes por planta na densidade de 10 plantas por metro, em que as plantas podadas resultaram em mais 3,2 vagens por planta (Figura 4). A densidade 30 foi inferior às demais densidades quanto ao número de vagens pequenas por planta (Figura 5). As densidades 10 e 15 apresentaram maior número de vagens grandes por planta em relação às densidades 20, 25 e 30 (Figura 6).

$\mathrm{O}$ número de sementes por vagem pequena não foi afetado pela poda nem pela densidade de semeadura, apresentando-se, em média, 5,1 $\pm 0,1$ sementes. Por outro lado, quando se utilizou densidade de 30 plantas por metro, ocorreram, aproximadamente, duas sementes a mais por vagem grande, nas plantas podadas, em relação às plantas não podadas (Figura 7).

A densidade de 30 plantas $\mathrm{m}^{-1}$ apresentou maior número de sementes por vagem grande, em relação às demais densidades das crotalárias podadas (Figura 7). Entretanto, nas plantas não podadas a densidade de semeadura não influenciou no número de sementes por vagem grande (Figura 7).

Queiroz et al. (2002), ao avaliarem algumas características agromorfológicas que participam da produção e produtividade de sementes de crotalária, encontraram em média quatro e cinco sementes por vagem. Os resultados encontrados no presente trabalho foram superiores aos encontrados por esses autores.

Com poda, obteve-se, aproximadamente, 305 e $271 \mathrm{~kg}$ $\mathrm{ha}^{-1}$ a mais de sementes das vagens grandes, em relação ao obtido com as plantas não podadas, nas densidades de 10 e 30 plantas por metro, respectivamente (Figura 8).

$\mathrm{O}$ peso de 1000 sementes de vagens grandes variou, aproximadamente, de 3,8 a 4,5 g, não ocorrendo efeito da poda nas densidades 10, 15 e 20 plantas por m. Para as densidades de 25 e 30 plantas por metro, houve efeito da poda, apresentando o peso de 1000 sementes, respecti-

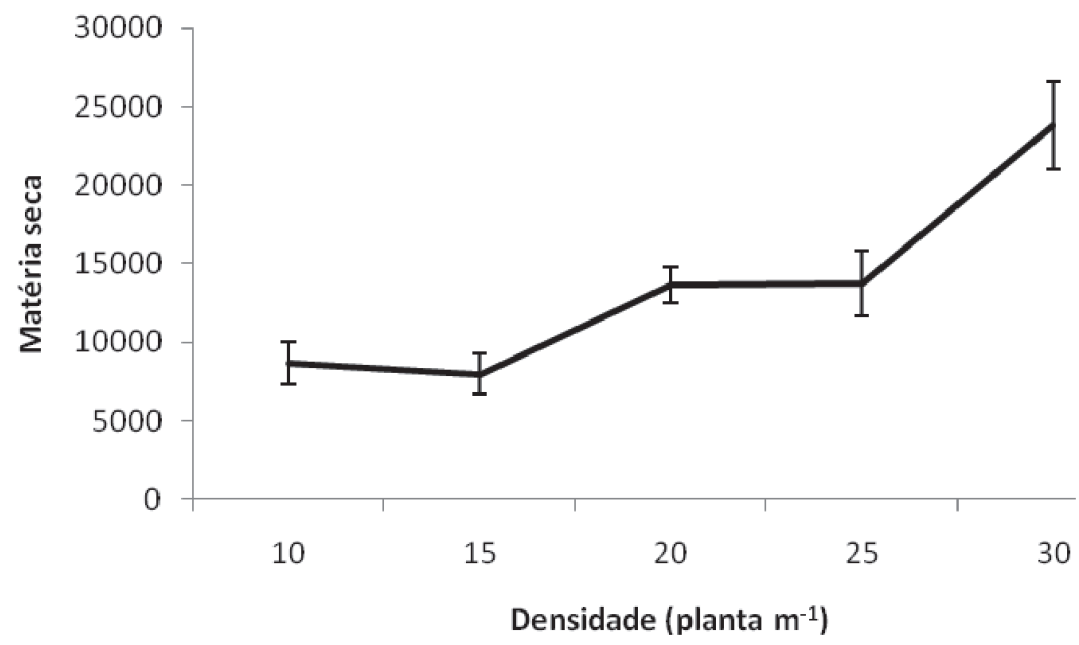

Figura 3 - Matéria seca de Crotalaria juncea $\left(\mathrm{kg} \mathrm{ha}^{-1}\right)$ obtida nas densidades de plantio de 10, 15, 20, 25 e 30 plantas por metro, aos 150 dias de cultivo (colheita).

Rev. Ceres, Viçosa, v. 59, n.5, p. 668-676, set/out, 2012 


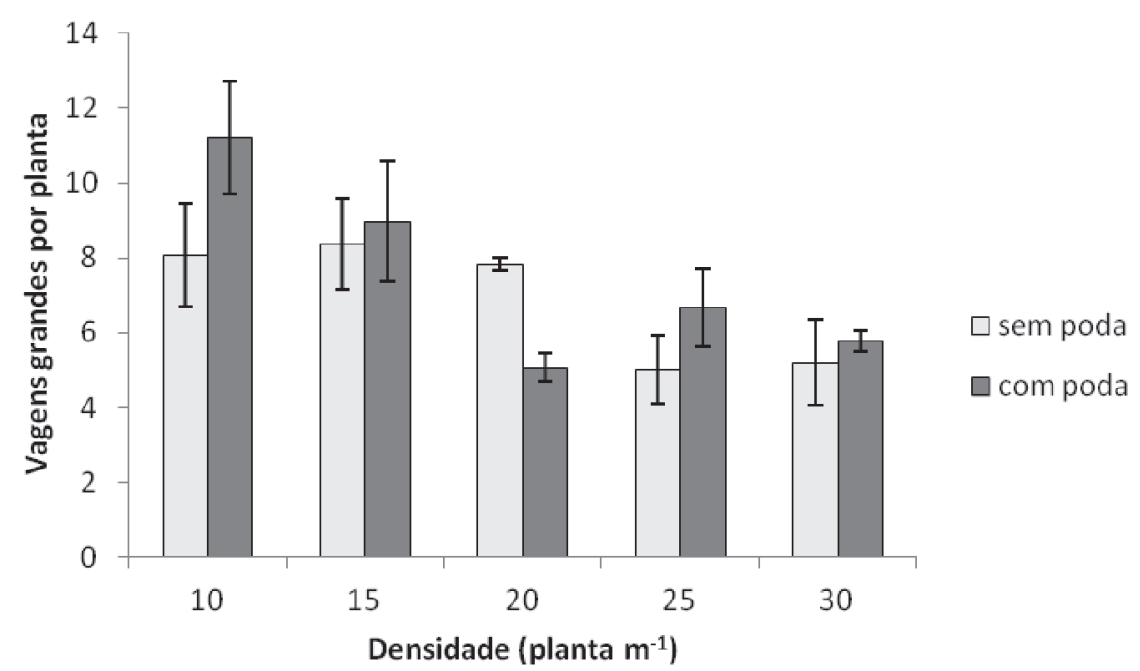

Figura 4 - Número de vagens grandes por planta de Crotalaria juncea manejada sem e com poda, nas densidades de plantio de 10, 15, 20,25 e 30 plantas por metro, aos 150 dias de cultivo (colheita).

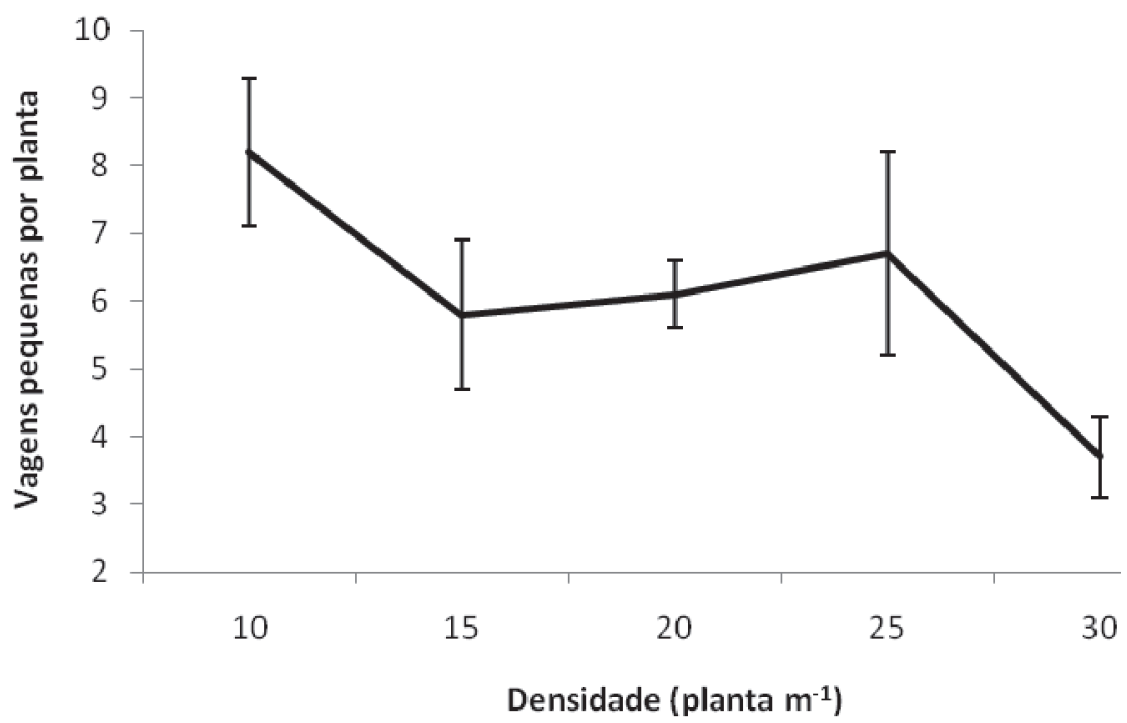

Figura 5 - Número de vagens pequenas por planta de Crotalaria juncea obtido nas densidades de plantio de 10, 15, 20, 25 e 30 plantas por metro, aos 150 dias de cultivo (colheita).

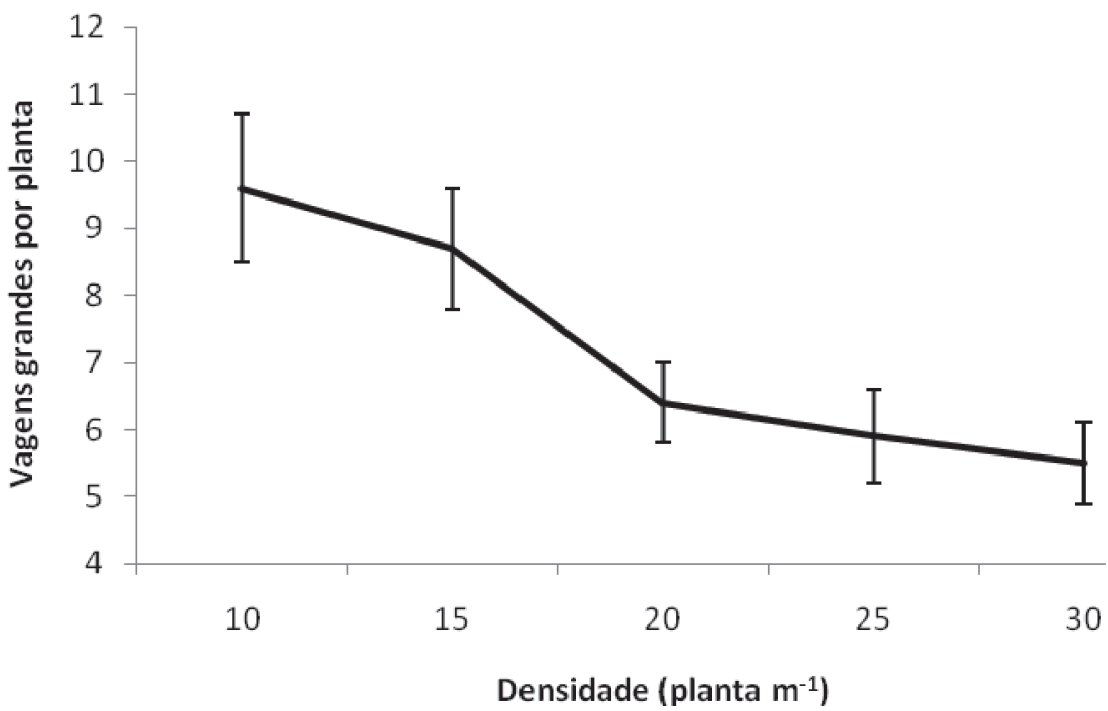

Figura 6 - Número de vagens grandes produzidas por planta de Crotalaria juncea obtido nas densidades de plantio de 10, 15, 20, 25 e 30 plantas por metro, aos 150 dias de cultivo (colheita). 


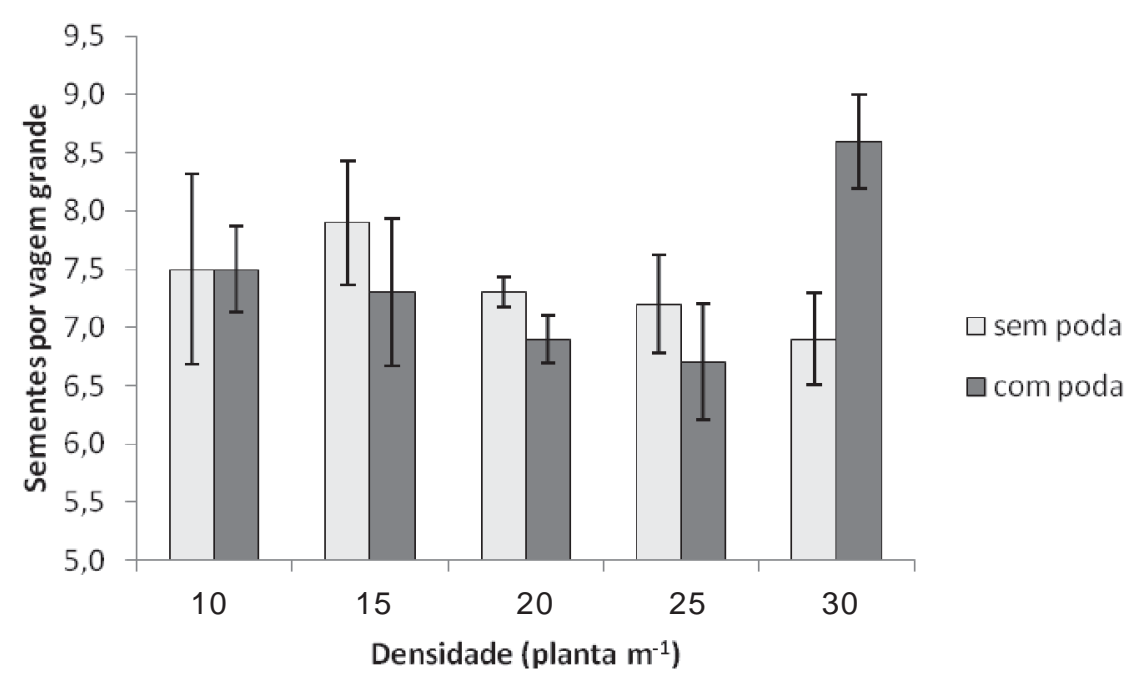

Figura 7 - Número de sementes por vagem grande de Crotalaria juncea manejadas sem e com poda, nas densidades de plantio de 10, 15, 20, 25 e 30 plantas por metro, aos 150 dias de cultivo (colheita).

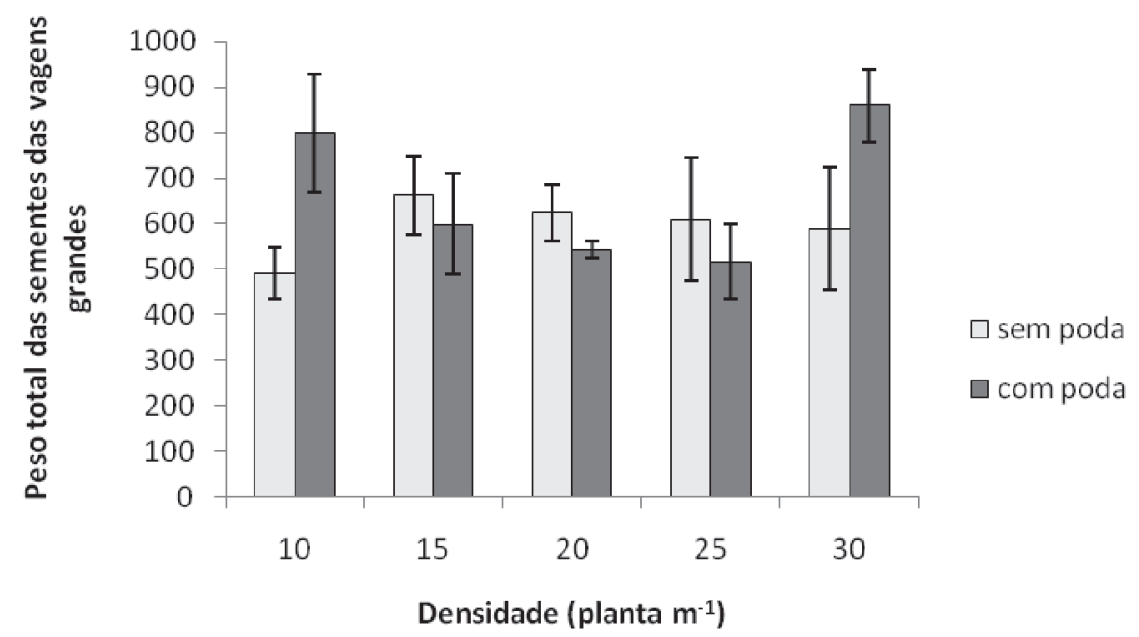

Figura 8 - Peso total das sementes $\left(\mathrm{kg} \mathrm{ha}^{-1}\right)$ das vagens grandes de Crotalaria juncea manejadas sem e com poda, nas densidades de plantio de 10, 15, 20, 25 e 30 plantas por metro, aos 150 dias de cultivo (colheita).

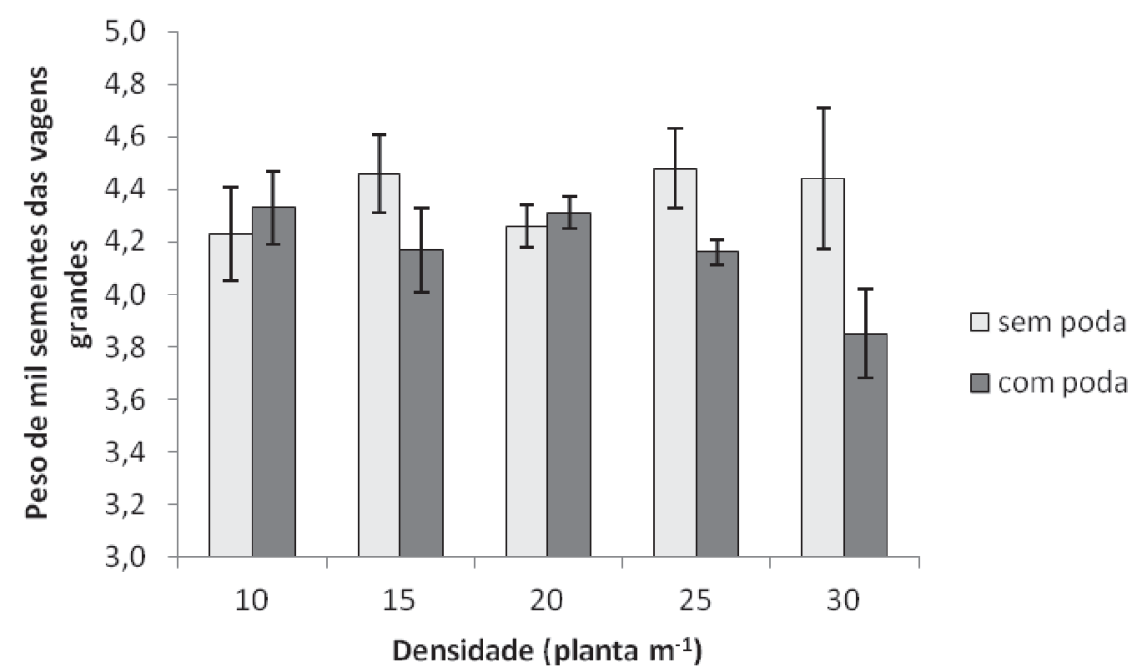

Figura 9 - Peso de mil sementes das vagens grandes (g) manejadas sem e com poda, nas densidades de plantio de 10, 15, 20, 25 e 30 plantas por metro, aos 150 dias de cultivo (colheita).

Rev. Ceres, Viçosa, v. 59, n.5, p. 668-676, set/out, 2012 
vamente, $0,32 \mathrm{~g}$ e $0,59 \mathrm{~g}$ a mais nas plantas não podadas, em relação ao das plantas podadas (Figura 9).

Ocorreu efeito das densidades sobre o peso de 1000 sementes das vagens pequenas (Figura 10). Observou-se que a densidade de 15 plantas por $m$ foi superior às densidades 20 e 25 . No entanto, a densidade de 15 plantas por metro não resultou em diferença em relação às densidades 10 e 30.

Entre as plantas podadas, as densidades de 10 e 30 plantas por metro apresentaram peso total de sementes das vagens grandes, em $\mathrm{kg} \mathrm{ha}^{-1}$, superiores em relação às densidades 15, 20 e 25; enquanto, sem poda, apenas a densidade de 10 plantas por metro foi inferior à de 20 , entretanto, ambos não diferiram das demais (Figura 11). Observa-se que ocorreu efeito da poda apenas nas densidades de 10 e 30 plantas por metro (Figura 11)

$\mathrm{O}$ aumento em função da poda, no número de vagens grandes por planta na densidade de 10 plantas de crotalária por metro (Figura 4), bem como no número de sementes por vagem grande, na densidade de 30 (Figura 7), certamente foram as razões dos incrementos observados, nestas densidades devido à poda. Vale ressaltar que a redução no peso de 1000 sementes causada pela poda, na densidade maior (Figura 9), não prejudicou os ganhos em produtividade.

Dourado et al. (2001), entretanto, avaliando o efeito de diferentes doses de fósforo, $614 \mathrm{~kg} \mathrm{ha}^{-1}$, com poda, e $600 \mathrm{~kg} \mathrm{ha}^{-1}$ sem poda, verificaram que a poda e a adubação fosfatada não alteraram a produção de matéria seca nem de grãos de Crotalaria juncea .

Observou-se que, a poda na crotalária com a densidade de 30 plantas por $\mathrm{m}$ apresentou maior peso total de sementes das vagens grandes por hectare (Figura 11); maior número de sementes por vagem grande (Figura 9) Isto é explicado pelo maior número de plantas por área, na densidade 30 , pois, mesmo com baixo número de vagens

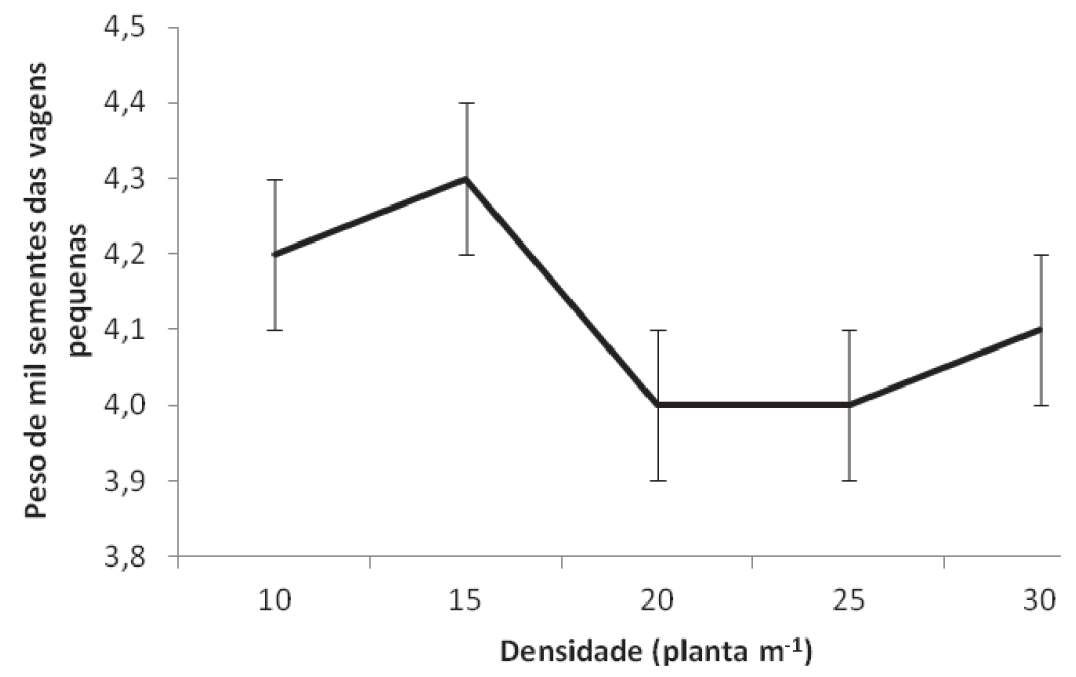

Figura 10 - Peso de mil sementes das vagens pequenas (g) obtida nas densidades de plantio de 10, 15, 20, 25 e 30 plantas por metro, aos 150 dias de cultivo (colheita).

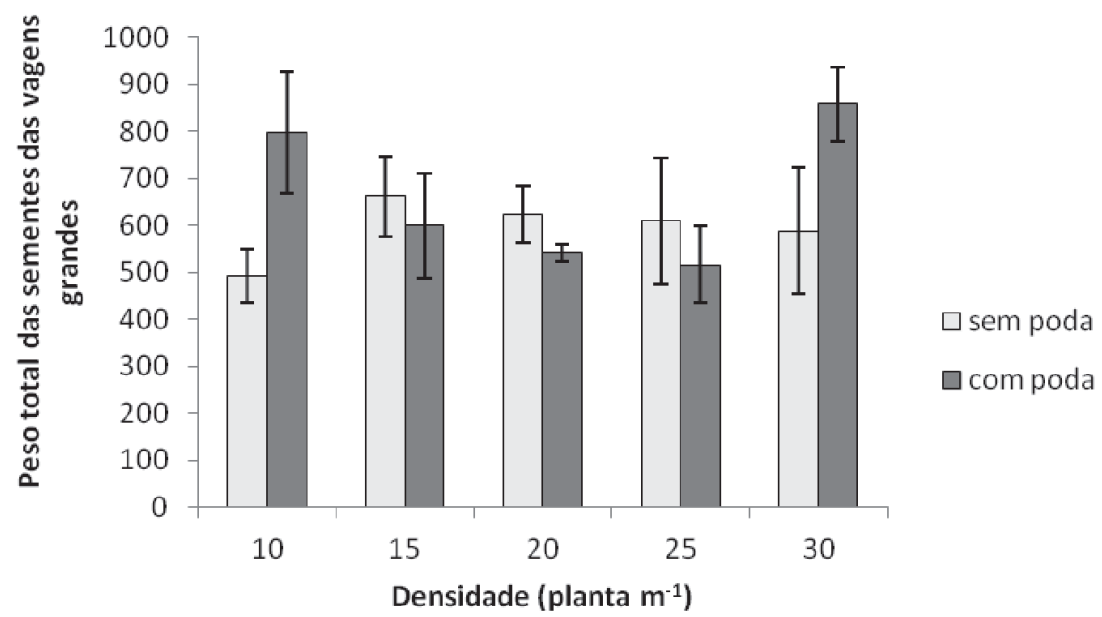

Figura 11 - Peso total de sementes das vagens grandes $\left(\mathrm{kg} \mathrm{ha}^{-1}\right)$ manejadas sem e com poda, nas densidades de plantio de 10, 15, 20, 25 e 30 plantas por metro, aos 150 dias de cultivo (colheita). 
por planta (Figura 6), obteve-se maior peso total de sementes. Já a densidade 10 apresentou maiores quantidades que as densidades 20 e 25; certamente, a maior produtividade nesta densidade está relacionada com o maior número de vagens grandes por planta (Figura 6) e com valores relativamente altos de peso de 1000 sementes de vagens grandes e pequenas (Figuras 9 e10).

Para as vagens pequenas, não houve efeito de poda ou densidade, apresentando em média $313 \pm 17 \mathrm{~kg} \mathrm{ha}^{-1} \mathrm{de}$ sementes.

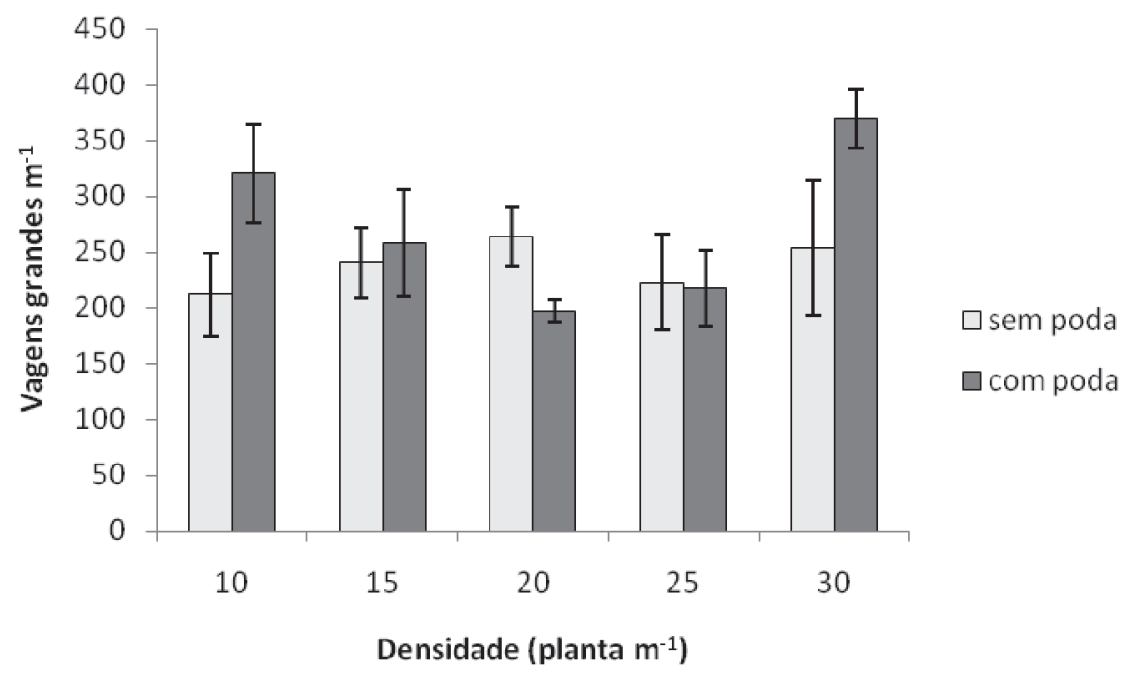

Figura 12 - Vagens grandes por metro em função das densidades 10, 15, 20, 25 e 30 e da presença e ausência de poda, aos 150 dias (colheita).

\section{CONCLUSÕES}

Recomenda-se a prática da poda, para a produção de sementes, em cultivo de Crotalaria juncea L.

As densidades de 10 e 30 plantas por metro apresentaram melhores resultados para produtividade, sendo a densidade de 10 plantas por $\mathrm{m}$ a que se mostrou mais satisfatória pelo menor gasto com sementes.

\section{REFERÊNCIAS}

Amabile RF, Fancelli AL \& Carvalho AM (2000) Comportamento de espécies de adubos verdes em diferentes épocas de semeadura e espaçamentos na região dos cerrados. Pesquisa Agropecuária Brasileira, 35: 47-54.

Alvarez VH, Ribeiro AC \& Guimarães PTG (1999) Recomendações para o Uso de Corretivos e Fertilizantes em Minas, $5^{\circ}$ aproximação, 359p.

Brasil, Ministério da Agricultura, Pecuária e Abastecimento (2009) Regras para análise de sementes. Ministério da Agricultura, Pecuária e Abastecimento. Secretaria de Defesa Agropecuária. Brasília, DF: Mapa/ACS, 395p.

Bulisani EA (1992) Adubação verde nos estados de São Paulo, Paraná, Santa Catarina e Rio Grande do Sul. In: Costa MBB (Coord.) Adubação verde no sul do Brasil. Rio de Janeiro: AS-PTA, p.57-195.

Calegari A, Moudardo A, Bulizani EA, da Costa MB, Miyasaka S \& Amado TJC (1992) Aspectos gerais da adubação verde. In: Costa MBB (Coord.). Adubação verde no sul do Brasil. Rio de Janeiro: AS-PTA, p.1-55.

Dourado MC \& Almeida CR (1998) Comportamento da Crotalaria juncea L. quando associada a três diferentes alturas de poda e duas densidades de plantas. In: Congresso de Iniciação cientifica, 10, Araraquara, 1998. Resumos. São Paulo: CNPq, 335p.
Dourado MC, Silva TRB da \& Bolonhezi AC (2001) Matéria seca e produção de grãos de Crotalaria juncea L. submetida à poda e adubação fosfatada. Scientia Agricola, 58: 287-293.

Duarte Jr JB \& Coelho FC (2008) Adubos verdes e seus efeitos no rendimento da cana-de-açúcar em sistema de plantio direto, Bragantia, 67: 723-732.

Nascimento JT \& Silva I de F da (2004) Avaliação quantitativa e qualitativa da fitomassa de leguminosas para uso como cobertura de solo, Ciência Rural 34: 947-949.

Perin A, Santos RHS, Urquiaga S, Guerra JGM \& Cecon PR (2004) Produção de fitomassa, acúmulo de nutrientes e fixação biológica de nitrogênio por adubos verdes em cultivo isolado e consorciado. Pesquisa Agropecuária Brasileira, Brasília, 39(1): 35-40.

Queiroz AO de, Lopes HM, Moreira LB \& Miyata OY (2002) Avaliação de características agromorfológicas na produção de sementes de crotalária (Crotalaria juncea L.). Revista Universidade Rural, Série Ciências da Vida, 22: 131-135.

SAEG Sistema para Análises Estatísticas e genéticas (2000) V.8.0. Viçosa, MG

Skora Neto F (1993) Controle de plantas daninhas através de coberturas verdes consorciadas com milho. Pesquisa Agropecuária Brasileira, 28: 1165-1171.

Taiz L \& Zeiger E (2002) Plant Physiology. Sinauer Associates Inc., 690p.

Wildner LP (1992) Utilização de espécies de verão para adubação verde, cobertura e recuperação do solo em Santa Catarina. In: Encontro Nacional De Rotação de Culturas, 2., Campo Mourão, 1992. Anais. Campo Mourão: AEACM, p.144-160.

Wutke EB (1993) Adubação verde, manejo de fitomassa e espécies utilizadas no estado de São Paulo. In: Writke EB, Bulisani EA \& Mascarenhas HAA. Curso de adubação verde no Instituto Agronômico, Campinas: Instituto Agronômico, p. 17-29. 